\title{
Fazendas de café oitocentistas no Vale do Paraíba
}

\begin{abstract}
Marcos José Carrilho ${ }^{1}$
RESUMO: As edificações remanescentes das fazendas de café do Vale do Paraíba constituem notáveis expressões da arquitetura rural paulista. $\bigcirc$ estudo de seus componentes e a compreensão de sua organização são aqui abordados mediante a leitura de textos, da época, sobre o cultivo de café e o exame de inventários de bens de seus proprietários. $\mathrm{Na}$ parte final, este enfoque é desdobrado na análise da arquitetura desses estabelecimentos. PALAVRAS-CHAVE: Fazendas de café. Vale do Paraíba. São Paulo. Arquitetura rural.
\end{abstract}

ABSTRACT: The architectural remnants of the old coffee plantation estates configure remarkable examples of São Paulo State (Vale do Paraíba) rural architecture. The study of their components, as well as the way in which they were established and organized, was carried out by means of readings of coffee plantation literature of the time, and by the analysis of owners' deeds. On the last part of this essay, the focus is extended to the analysis of the remaining architecture of such edifications.

KEYWORDS: Coffee plantations. Vale do Paraíba. São Paulo. Rural architecture.

Introdução

Quem se defronta com os remanescentes de fazendas de café no Vale do Paraíba logo se impressiona pela imponência das edificações típicas desses estabelecimentos, particularmente, da residência principal. Mas logo sobrevém certa desolação ao verificar estarem elas isoladas na paisagem, desprovidas do vasto conjunto de instalações que as compunha. Dificilmente o observador será capaz de fazer idéia do movimento e da atividade que assistiram. Uma sucessão contínua de casas formando pátios, com instalações de beneficiamento, engenho, moinho, tulha, oficinas do ferreiro e do carapina, senzala, enfermaria, casa do administrador, rancho, venda, pouso; e gente, muita gente. Cinqüenta,

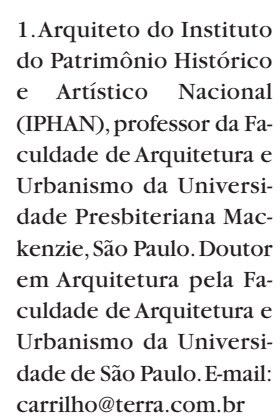

1.Arquiteto do Instituto do Patrimônio Histórico Artístico Nacional culdade de Arquitetura Urbanismo da Universidade Presbiteriana Mackenzie,São Paulo. Doutor em Arquitetura pela Faculdade de Arquitetura e dade de São Paulo.E-mail carrilho@terra.com.br 
3. Como mostram os títulos que transcrevemos aqui. Pelo socio effectivo José Rezende Costa. Me mória sobre o café: comércio, propriedades uso, cultura e preparação do café.Traduzido do novo Curso de Agricultura, redigido pelos Membros da Secção de Agricultura do Instituto de França (n 11, 1834); Pelo Exmo. Sr Conde de Gestas. Memória sobre os abusos das derrubadas e cortes de madeiras (n. 1, 1837); Um cylindro para descerejar $1000 \mathrm{lb}$ de café por hora...(v. 12, n. 4, 1844); Notícia de uma nova estufa, fácil e economica para seccar com perfeição o café e outros gêneros de nossa produção agrícola (v. 13, n. 5, 1845); Café do Brasil nos Estados Unidos (n. 1, 1846); Memória para melhorar a sorte de nossos escravos (v. 14 1846); Quais os meios mais adequados de substituir no Brasil os braços escravos pelos livres? (v 14, 1846); Reflexões sobre a escravatura das fazendas do Brasil (v. 14 1846); Memória do Sr. Dr E. J. da Silva Maia. Café história, descrição, cultura, colheita, e todas as suas propriedades (v. 15 , n. 8, 1848); Por um fazendeiro desta Província. Café: cultura e colheita no Rio de Janeiro (n. 1, 1847); Taunay. Reflexões sobre a escravatura e colonização (v. 15, 1848); Sr. F. L. C. Burlamaque. Reflexões sobre a escravatura e colonização no Brasil (v. 15, 1847);A produção do café (v. 17, n. 11, 1850); Repressão do trá fico (v. 18, 1850); A repressão do trafico e a colonização (v. 18, 1850); Trabalho livre e escravo. (v. 18, 1850); Preparação do café (1858). cem, cento e cinqüenta escravos, a maioria para o serviço da lavoura, mas também para a atividade doméstica e para os ofícios de ferreiro, moleiro, cavouqueiro, pedreiro e tantos outros. E, ainda, o administrador, o capataz, o feitor e o tropeiro. E, finalmente, a paisagem, a sucessão de colinas riscadas pelas carreiras de cafeeiros. Quase tudo desapareceu. Restaram apenas esses enormes edifícios residenciais, às vezes um pomar, uma aléia de jabuticabeiras ou um renque de palmeiras imperiais a anunciar, à distância, a presença da sede da fazenda. Talvez algum vestígio de construções complementares, principalmente os muros, os alinhamentos das fundações e os vastos terraplenos, antes superfícies pavimentadas, agora recobertas de grama. $\bigcirc$ movimento deu lugar ao ar modorrento de um ambiente rural desabitado, onde a atividade porventura persistente não mais corresponde à modesta expressão da riqueza ali produzida. Riqueza tão grande quanto fugaz.

Uma das áreas pioneiras de desenvolvimento da cultura do café teve origem no chamado Caminho Novo da Piedade, ligação terrestre aberta no século XVIII entre as províncias de São Paulo e do Rio de Janeiro. Iniciada a partir de Lorena, essa estrada passa por Silveiras, Areias, São José do Barreiro e Bananal, prosseguindo por Rio Claro, São João Marcos e ltaguaí na direção do Rio de Janeiro. Esta região, conhecida como o "fundo do vale" assistiu, durante o século XIX, um vertiginoso processo de desenvolvimento, dando origem à formação de alguns dos mais ricos estabelecimentos de café daquele período. Para compreender a organização de suas instalações, sua arquitetura, as formas e os padrões, as variações e as particularidades que distinguem uma fazenda de outra, é necessário recorrer às fontes capazes de permitir a reconstituição, ainda que parcial, de alguns aspectos desse mundo. Para tanto há, de um lado, o que talvez possa ser chamado de literatura "agronômica" do século XIX e, de outro, os inventários dos proprietários de fazendas. Tais fontes permitem explorar aspectos pouco estudados do tema e, de algum modo, desvendar como eram concebidas e como funcionavam estas unidades produtivas.

A literatura "agronômica"

Ao longo do período inicial de consolidação da cultura do café, na primeira metade do século XIX, surgiu grande variedade de textos que descreviam técnicas de implantação das lavouras, máquinas e inventos e que discutiam a vantagem deste ou aquele método de beneficiamento. Embora a maioria se dirigisse a aspectos muito específicos - descrições monótonas e meticulosas de equipamentos e dados comparativos -, não foram poucas as iniciativas visando à difusão e ao aperfeiçoamento da produção. Em 1832, foi fundada a Sociedade Promotora da Civilização e Indústria da Vila de Vassouras². No ano seguinte, começa a ser publicado o jornal $O$ Auxiliador da Indústria Nacional, que permanece em circulação até 1892. O periódico reúne várias "Memórias" sobre o cultivo do café, e divulga "Notícias" de máquinas e equipamentos de beneficiamento; ou discute os problemas decorrentes do sistema apoiado no trabalho escravo ${ }^{3}$. À época, além desse 
importante periódico, há várias outras obras publicadas por editoras brasileiras ${ }^{4}$. A importância de tais publicações pode ser percebida em alguns relatos, como o do naturalista norte-americano Herbert $\mathrm{H}$. Smith. Ao descrever o interior da residência de uma fazenda de café na Província do Rio de Janeiro, em meados do século XIX, o cientista comenta:

"A sala de jantar é grande e de paredes lisas; de um lado há uma escrivaninha com alguns livros, notadamente manuais agrícolas, em português e francês". E, mais adiante, acrescenta: "Nem um livro sequer na sala; aliás, não existem outros na casa além dos manuais de agricultura" ${ }^{5}$.

Por outro lado, autores que se dedicaram ao estudo desses estabelecimentos, como o arquiteto Luis Saia ${ }^{6}$, aludem a obras importantes, como - Tratado de Labourie, sem, contudo, deterem-se em sua análise. Eduardo Silva”, no belo ensaio que introduz a reedição do texto do barão de Paty do Alferes, embora destaque a discussão das técnicas agronômicas, trata o tema num grau de generalidade que não permite aproximação às especificidades da organização dos estabelecimentos de café. É necessário, portanto, examinar diretamente estas fontes, a fim de ampliar a compreensão dos exemplares pioneiros da cultura do café.

A obra de maior interesse (e também a mais antiga) é $\bigcirc$ fazendeiro de café da ilha de São Domingos, de P. J. Laborie ${ }^{8}$. Traduzido para o português em 1799, esse texto, além de pioneiro, certamente foi a referência mais importante para o desenvolvimento da cultura do café no Brasil. Evidências de sua influência podem ser recolhidas no artigo de José Silvestre Rebello, publicado no jornal da Sociedade Auxiliadora da Indústria Nacional, de 1833: "Dos tratados sôbre a cultura do cafeeiro, aquelle que a prática tem provado melhor, he o de Mr. Laborie $[\ldots]^{\prime \prime 9}$.

Há, contudo, outro texto que se destaca não apenas por discorrer sobre os modos e procedimentos afetos a esta cultura, mas que surge como verdadeiro documento de uma época. Trata-se da Memória sobre a fundação de uma fazenda na Província do Rio de Janeiro ${ }^{10}$, de Francisco de Lacerda Werneck, barão de Paty do Alferes, que é, dentre os textos pioneiros surgidos no Brasil, o mais importante. Editada pela primeira vez em 1847, a Memória nos oferece referências preciosas sobre as formas de organização dos estabelecimentos de café no Brasil.

A obra de Laborie, no entanto, destaca-se pela capacidade de expor de forma sistemática e exaustiva todas as etapas necessárias à implantação de uma fazenda de café. Logo de início, são descritas as preocupações fundamentais em relação à escolha do sítio e às características dos assentamentos. $\bigcirc$ planejamento do empreendimento, isto é, a capacidade definir previamente um objetivo e traçar os meios de alcançá-lo, fica claramente manifesto. Às recomendações quanto à distribuição de plantações, "[...] reservando sempre bastantes, e proporcionadas matas, para suprirem as terras de Café já cansadas"11, associa-se a preocupação com o sítio das edificações: "Se cahio no erro de não escolher a situação mais favorável para a posição dos edifícios, ainda he tempo de o emendar $[\ldots]^{\prime \prime 2}$. E o autor acrescenta que somente nas
4. Aguiar, J. J. F. de. Pequena memória sobre a plantação, cultura e colheita do café... Rio de Janeiro: Imprensa Americana, 1836; CALDEIRA,A.da S.Memória sobre um novo métbodo de preparar café... Rio de Janeiro:Typ. Universal de Laemmert, 1843; BURLAMAQUI, F. L. C.Manual de máquinas, instrumentos e motores agrícola... Rio de Janeiro:Typ. De N. L.Vianna \& Filhos, 1859.

5. SMITH, H. H. Uma fazenda de café no tempo do Império. Rio de Janeiro: Departamento Nacional do Café, 1941,p. 8.

6.SAIA, L.A morada paulista.São Paulo: Perspectiva, 1972, p. 180.

7. SILVA, E. O Barão de Paty do Alferes e a fazenda de café da velha Província. In: WERNECK, F.P.L. Memória sobre a fundação de uma fazenda de Café na Província do Rio de Janeiro. Rio de Janeiro: Senado Federal; Fundação Casa de Rui Barbosa, 1985, p. 30.

8. LABORIE, J. P. O fazendeiro de café na ilha de São Domingos. In: $O \mathrm{fa}$ zendeiro do Brazil.Tomo 3, Parte 2. Rio de Janeiro: Officinas de S.T. Ferreira, 1799.

9. REBELLO, José Silvestre. Memória sobre a cultura do Cafeeiro. O Auxiliador da Indústria $\mathrm{Na}$ cional, Rio de Janeiro, $\mathrm{n}$. 5, p. 2,1833 .

10. WERNECK. op. cit.

11. LABORIE, P. J. op. cit., p. 47 .

12. Idem, p. 50 
13. Idem., p. 50-51

14. Ibidem.

15. Idem, p. 51

16. WERNECK, F. P. , op cit., p. 57. terras "[...] de mui pequeno declívio póde-se conseguir hum arranjo regular, e simétrico no dispor os lugares para os edificios" ${ }^{\prime 13}$. Tal advertência é ilustrada com "[...] dous planos de huma das mais regulares plantações de S. Domingos $[. . .]^{114}$. Portanto, não apenas a ilustração abstrata de um modelo ideal, mas (embora um caso excepcional, devido à sua regularidade) uma indicação fundada na realidade (Figura 1).

Prosseguindo, Laborie observa que,

"[...] quanto ás casas, sua exposição deve ser nos montes os mais accessíveis, e de ordinário na sumidade de alguns outeiros os mais extensos, e largos e menos ingrimes, que se acharem, e para onde se possa conduzir agua. Nelles se arranião os diversos estabelecimentos, quanto póde ser, á vista, e alcance da casa de morada, e á industria compete tirar da situação a mór vantagem possível"15.

Além do cuidado de situar as plantações, tanto quanto possível, eqüidistantes, é desejável implantar a residência do proprietário de modo a garantir o domínio visual das instalações, evidenciando o propósito do controle do conjunto das atividades.

Da mesma forma, a obra de Werneck inicia-se pelas considerações a propósito da localização do estabelecimento: "O primeiro cuidado que deve ter o fazendeiro que de novo se estabelece e que vai fundar uma fazenda é procurar aguada, e se a houver tirar-the o nível com direção a melhor localidade"16.

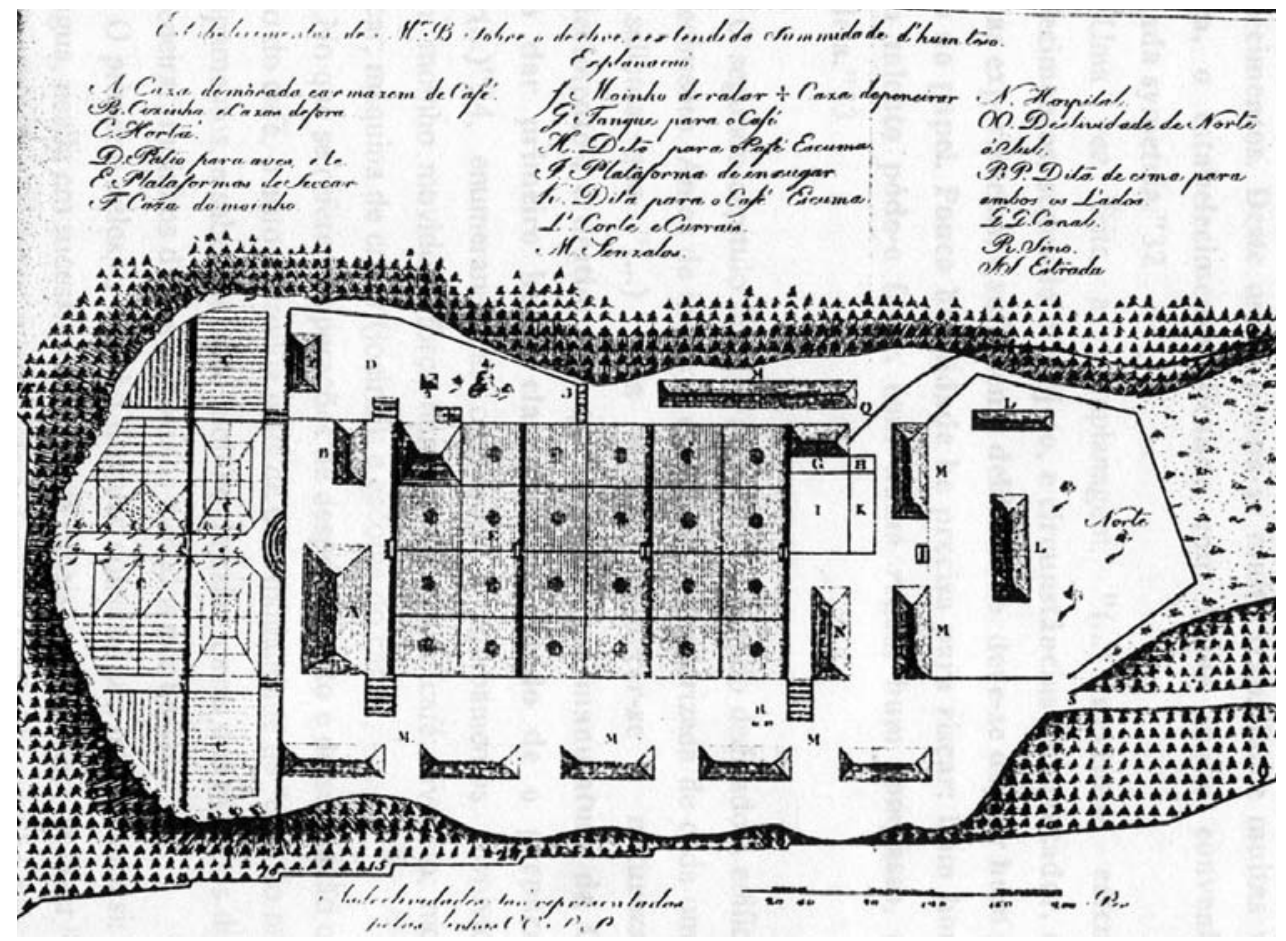

Figura 1 - Planta e perfil do estabelecimento de Mr. B. Em LABORIE, P. J. O Fazendeiro de Café na llha de S. Domingos (VELLOSO, 1799). Acervo da Biblioteca Guita e José Mindlin, São Paulo. 
Já no primeiro parágrafo, é nítida a preocupação em encontrar o sítio apropriado. Decorrente da necessidade de dispor da água para o aproveitamento da energia hidráulica, essa precaução é confirmada a seguir, pois "se não houver remédio, se não fizer as obras à feição da altura que ela der, não a podendo levar aonde se quer, aí mesmo fundará a fazenda, e eis o motivo por que muitos e grandes estabelecimentos estão feitos sem aformoseamento [... $]^{\prime 17}$.

Ênfase semelhante era dada, na obra de Laborie, ao projeto do estabelecimento:

He porém ainda mais necessario hum plano dos estabelecimentos, propriamente ditos, como edifícios, plataforma, e casas; pois se fazem á aventura hum depois do outro, como várias vezes sucede, póde acontecer ficar o primeiro no lugar, em que depois se conhece, que devia ficar o outro; e não se guardar á symetria, que custa pouco, e sem o que as melhores cousas são desengraçadas, e perdem muito do seu merecimento ${ }^{18}$.

Trata-se da necessidade de deter a compreensão do conjunto das atividades desenvolvidas no estabelecimento, de modo a permitir o encadeamento adequado de suas articulações. Para a obtenção do arranjo mais eficaz sob o aspecto da produção, procura-se afastar as iniciativas fruto do acaso e da improvisação. Evidentemente estamos diante de um princípio de projeto, anunciado pela faculdade de antecipação característica desta atividade. Tal preocupação não negligencia sequer a dimensão estética, em que o gosto pela simetria é ressaltado junto à sua adequação econômica.

Assim, "[...] devem-se calcular os estabelecimentos, segundo o projeto, e circunstâncias do plantador, e depois de várias experiências, e sufficiente deliberação, deve-se doptar hum plano, e riscallo no papel". Mesmo na ausência de arquiteto ou engenheiro experiente, a importância do projeto não deverá ser negligenciada, pois "pouca habilidade he precisa para riscar: hum homem de comum talento póde-o fazer, com huma regoa, hum compasso, e huma esquadria" 19 .

No texto de Werneck, definido o conjunto de instalações necessárias, são alinhadas as providências a serem tomadas, em conformidade a uma seqüência diligentemente programada: "Principiareis a vossa fazenda edificando primeiro uma casa ordinária para a vossa moradia temporária, e tantas quantas forem precisas para acomodar os escravos e camaradas; mas tudo isto deve ser feito de forma que não estorve o risco da fazenda"20. Convém, portanto, alertar ao fazendeiro da importância de planejar o processo de assentamento. Uma vez construídas as moradias provisórias, devido ao papel fundamental da água, Werneck recomenda executar, em seguida, "o rego que deve trazer água para tocar as fábricas [... $]^{\prime 21}$. Com o propósito de evitar desperdício e controlar os gastos, aquele autor observa ainda que a "primeira obra que se deve fazer é o engenho de serrar, que fará com que a vossa fazenda vos custe a metade do que custaria $[. . .]^{\prime \prime 22}$. E, finalmente, numa seqüência lógica, à execução do engenho de serrar deve suceder a do moinho, do engenho de mandioca e dos pilões.
18. LABORIE, J. P., op. cit., p. 52-53.

19. Idem, p. 54

20. WERNECK, F. P., op. cit., p. 57.

21. Ibidem.

22. Ibidem. 
23. LABORIE,P. J., op. cit., p. 118.

24. Ibidem.

25. Idem, p. 120.

26. WERNECK, F. P., 1985 p. 68 .

27. LABORIE, P. J., 1799 , p. 137

28. Ibidem
A preocupação de Laborie com o beneficiamento se manifesta particularmente na execução dos terreiros. Estes não precisam ser construídos de uma só vez e sim "[...] a proporção que se augmentar o producto, mas sempre segundo um plano geral. Seus perfis, ou figura, dependem muito da situação do terreno; o principal he aproveitar a situação, fazendo de modo que se forme a mais extensa superfície com o menor gasto" 23 .

Novamente desponta a importância atribuída ao projeto e ao planejamento, visando a dosar as energias e evitar erros que possam trazer problemas futuros. Ao serem considerados os nivelamentos, o cuidado com as características do sítio se evidencia ainda mais. Especialmente nos locais onde - "declívio excede dous ou tres pés para cada platafórma, he então menos dispendioso cortallas em amphiteatro huma acima da outra"24. A construção do terreiro é feita por meio de três operações distintas: fundos ou pavimentos, incrustação ou reboque, e a operação final de alisar ou polir. Além do "declívio" e da pavimentação, o terreiro deve ser dotado de "pequenas aberturas para dar sahida á agua da chuva" junto às bordas ${ }^{25}$. Portanto, na execução dessas plataformas, atenção especial é dirigida ao sistema de drenagem. Tal cuidado decorre da necessidade de sempre manter sem nenhuma umidade as vastas áreas destinadas à secagem do produto, cultivado quase sempre em regiões de altos índices pluviométricos.

Em contraste, a descrição dos terreiros de Werneck revela um dos graves problemas do beneficiamento do café no Brasil. Neste caso, os terreiros de café, pelo menos na primeira metade do século XIX, eram predominantemente de chão batido. É isso que justifica o tratamento tão sumário presente na Memória: "O terreiro deve ser feito com algum declive bem direito e duro, a fim de escorrer facilmente com as águas e não enterrar o grão" 26 .

Uma vez estabelecidas as condições e os locais para cultivo e beneficiamento, seguem-se as indicações relativas às residências. Para Laborie, as senzalas possuem diferentes comprimentos, a depender da natureza do lugar, mas jamais podem exceder cento e cinqüenta pés de comprimento. A largura deverá ser de vinte pés e a altura debaixo do teto, de sete ou oito pés. "A cada tres negros se concedem déz pés para perto de vinte, que elles dividem em dous quartos; hum A, onde se faz fogo, outro, B, para dormir. Pode-se acrescentar por detraz huma galaria, C, da largura de seis pés, para suas aves." ${ }^{27}$ (Figura 2). Constata-se aqui, mais uma vez, um grau de refinamento maior, se comparado aos padrões dos agricultores brasileiros. As descrições conhecidas destes edifícios no Brasil não mencionam a subdivisão das senzalas, adotando, quando muito, um alpendre corrido, como a "galaria" atrás referida. Esta edificação, entretanto, não se destina à criação de aves, mas tem a função de oferecer proteção à circulação dos escravos entre os cubículos.

A ventilação e a orientação não são negligenciadas nessas dependências, evidenciando a preocupação com a salubridade, uma vez que os escravos constituem o patrimônio mais importante destes estabelecimentos. "Dever-se-ha deixar passagem livre ao ar, alias deverão as portas todas ficar voltadas para Leste; ou Sul." 28 


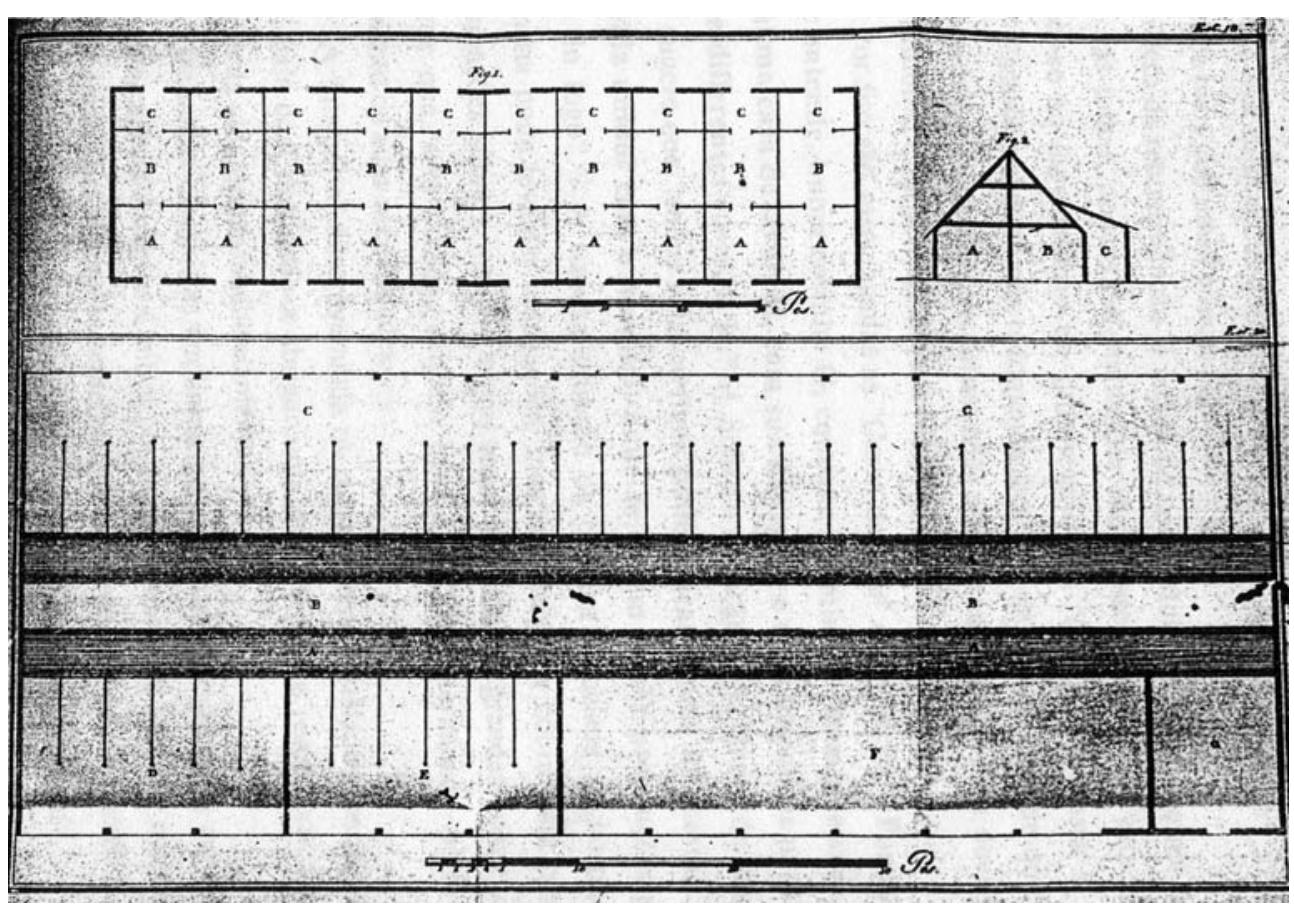

Figura 2 - Planta das senzalas. LABORIE, P. J. O Fazendeiro de Café na llha de S. Domingos (VELLOSO, 1799). Acervo da Biblioteca Guita e José Mindlin, São Paulo.

Contrastando com as descrições minuciosas das edificações anteriormente referidas, a residência principal, no texto de Laborie, não merece mais do que umas poucas linhas. Deixa-se ao livre arbítrio do proprietário e à "sua fantasia a fórma dellas". Apesar desta liberalidade, o autor adverte que "a casa deve ser sadia, cômmoda, e sufficiente para a família"29.

As senzalas também são dependências que merecem destaque na Memória de Werneck. A descrição dessas moradias chega a minúcias tais como a sugestão de que devam ser feitas "[...] em uma só linha, se for possível, com quartos de 24 palmos em quadro". A exemplo do modelo traçado por Laborie, Werneck aconselha a construção de varandas "de oito de largo em todo o comprimento" ${ }^{30}$. Esse cuidado justifica-se em função dos requisitos de salubridade, argumentando que elas "[...] são de muita utilidade porque o preto, na visita que faz a seu parceiro, não molha os pés se está a chover; quase sempre estão eles ao pé do fogo, saem para o ar frio e chuva, constipam, e adoecem" ${ }^{\prime 31}$.

Os inventários de fazendas de café

Feita esta primeira aproximação a partir dos textos dirigidos ao cultivo do produto, é necessário recorrer a outro tipo de fonte documental - os inventários 
de proprietários de fazendas -, a fim de ampliar a compreensão dos testemunhos materiais que chegaram ao nosso tempo.

O universo de inventários consultados é largo, compreendendo: a fase inicial de produção do café, especialmente a década de 1830; o período de grande prosperidade, entre os anos quarenta e sessenta; e a decadência do cultivo no Vale do Paraíba, nas três últimas décadas do século XIX. A análise efetuada não pretendeu traçar a trajetória de um ciclo, nem expor os conflitos característicos deste sistema produtivo, notadamente em relação à mão-de-obra escrava. Tampouco se deteve sobre as diferenças cronológicas dos vários estágios da produção, refletidos nas mudanças e variações características dos remanescentes dos estabelecimentos de café. $O$ intuito foi explorar as potencialidades dessas fontes documentais pela simples comparação de seus dados quantitativos, mesmo quando consideradas as limitações decorrentes da justaposição de séries de distintos períodos cronológicos. Para o fim da reconstrução de formas arquitetônicas recorrentes e de tipologias características da organização destes estabelecimentos, este tipo de manipulação não só é pertinente como tem-se revelado bastante esclarecedor.

Um arrolamento de inventário é uma descrição regida pelo propósito de quantificar o valor de determinado conjunto de bens para fins de sua distribuição entre os sucessores do inventariado. Portanto, nesse tipo de documento, é mais importante indicar precisamente os componentes inventariados, de modo a permitir estabelecer o valor do patrimônio, do que se deter em suas características ou perder-se em juízos subjetivos. Trata-se de uma descrição impessoal, que dá conta daqueles bens que se traduzem em valor mercantil, com o propósito de avaliar o "monte-mor" de alguma partilha. Ali não interessam os atributos de "aformoseamento", mas apenas a quantidade de lanços ou casas, suas dimensões e as características dos equipamentos.

Além de predominante, o critério quantitativo é muito importante para a análise histórica, pois possibilita identificar não apenas o porte da propriedade, mas a extensão das atividades, a diversidade das instalações necessárias à produção; e fornece também evidências de ordem funcional que, em última análise, constituem atributos de qualidade. Apesar disso, os inventários deixam escapar, muitas vezes, descrições que falam da robustez da casa, das particularidades de sua fatura ou referências à sua forma, o que permite algumas aproximações de ordem qualitativa.

Em um estudo de particular interesse para a compreensão da arquitetura rural do café, o arquiteto Luis Saia vale-se dos arrolamentos de inventários para fundamentar a sua interpretação. Para ele, o terreiro é o elemento gerador dos agenciamentos característicos dos estabelecimentos rurais, constituindo o principal fator que os distingue das outras modalidades de construções rurais. Para demonstrar seu argumento, recorre ao inventário da fazenda Formoso, que traz a seguinte descrição:

Uma casa para dormitório dos pretos no terreiro da fazenda; huma outra casa no mesmo terreiro com 30p. que serve para tulha de arroz; huma casa já velha no mesmo terreiro que serve para paiol; huma casa no mesmo terreiro que serve para galinheiro; cinco lanços de 
casas no mesmo terreiro, assoalhadas, e que servem para tulhas; huma casa no mesmo terreiro com engenho de secar café e seus pertences; hum moinho para moer milho, com casa no mesmo terreiro; huma casa no mesmo terreiro que serve para tropa coberta de palha; huma casa de sobrado no terreiro da fazenda e que hé casa de morada $[\ldots]^{32}$.

Comentando a singularidade deste arrolamento, aquele autor conclui que "o que interessa no inventário da citada fazenda Formoso é a explicitação do agenciamento de suas diferentes partes: nove unidades de construção se voltam para o terreiro" ${ }^{\prime 3}$.

Este caso, porém, é uma exceção. Há apenas um outro inventário no qual se repete essa mesma sistemática descritiva. Trata-se da fazenda Marrecas. Nesta, porém, há mais de um terreiro, como é usual. Por outro lado, verifica-se que os terreiros, além de não serem mencionados tão freqüentemente, como seria necessário para atender àquele argumento, são referidos, muitas vezes, de forma indireta. Num universo de mais de setenta inventários de fazendas, em trinta e cinco são mencionados terreiros e, em dezenove deles, as referências são indiretas:

Quatro porteiras feicho do terreiro [...] [fazenda Arribada, 1856]; duas passagens cobertas no quadro do terreiro [...] [fazenda Mato Dentro, 1868]; [...] murado o terreiro de adobos, e tão bem coberto de telhas, com hum portão de entrada outro de saida [...] [fazenda Perapetinga, 1836]" ${ }^{\prime \prime 4}$

Quanto às características do seu agenciamento e à maneira como participam na organização do conjunto das instalações, nada pode ser afirmado de forma conclusiva. A associação a outras edificações é casual, resultante mais da seqüência da descrição e da situação física de determinadas instalações do que de algum nexo específico.

Assim, tanto podem comparecer "tres lanços de casas terreas cobertas de telhas com duas portas [... . na frente do terreiro" (fazenda Glória dos Campos, 1838); como "sete lanços de casas de sapé no terreiro de dentro" (fazenda Santa Vitória, 1859); ou o "rego d'água no terreiro coberto de rachões; uma casa [...] de frente para o terreiro de dentro" (fazenda Quilombo, 1856). Não há regra e não há sistemática, sendo arriscado estabelecer, a partir dos inventários, vínculos funcionais ou seqüência lógica de distribuição das instalações relacionadas com o terreiro.

É comum, também, a existência de mais de um terreiro. Na fazenda da Barra, em São José do Barreiro, são arrolados "tres terreiros feitos de pedra e cal para secar café"; na fazenda Quilombo, "hum lanço em aberto com mais quatro seguintes no terreiro de fora a maior parte deles fazendo frente para o terreiro de dentro". Contíguos ou separados, de dentro, de fora ou simplesmente definidos com a expressão "terreiros", no plural, há pelo menos treze inventários em que tais instalações comparecem assim mencionadas.

A organização fechada em torno do terreiro, por sua vez, não se afigura como regra única, tanto pela presença de mais de um terreiro, como pela referência de sua localização. Os limites dos terreiros são vinculados, com
32 SAIA, Luis. Notas preliminares sobre a fazenda Pau d'Alho. Separata de: Revista de História, São Paulo, n. 102, p. 609 , 1975.

33. Ibidem

34. Todos os inventários citados encontram-se nos arquivos do Conselho de Defesa do Patrimônio Histórico,Arqueológico, Artístico e Turístico do Estado de São Paulo (Condephaat), tendo sido coligidos por Carlos Eugênio Marcondes de Moura. 
35.TAUNAY,A.E. História do Café. tomo II. Rio de Janeiro: Departamento Nacional do Café, 1939 . p. 384 muita insistência, aos "paredões de pedra"; aos "muros que sercão o terreiro" (fazenda Formoso); às "oitenta braças de taipa larga e alta que serca o terreiro de dentro" (fazenda Sebastopol); ou à "cerca do terreiro [...] de arame farpado [...]" (fazenda Glória dos Campos). A constatação permite inferir que nem todas as instalações estão contidas no "quadro" da fazenda; e que tampouco os terreiros são envolvidos inteiramente pelo conjunto das edificações.

Esta análise não retira o mérito da síntese explicativa que Saia buscou estabelecer a propósito do papel dos terreiros na organização da fazenda de café. Apenas os apresenta em sua condição relativa e, em função das informações disponíveis, procura verificar até que ponto a condição de elemento estruturador da organização do estabelecimento é o fator predominante.

Sob o aspecto do beneficiamento do café, o exame dos inventários revela considerável diversidade de equipamentos e técnicas utilizados. Os arrolamentos consultados não permitem distinguir muito claramente entre as várias modalidades de engenhos. Mencionam genericamente o "engenho de soque" ou a "machina de soccar". Em setenta inventários pesquisados, foram contados apenas vinte e oito engenhos ou maquinismos para café. Dezessete deles são descritos explicitamente com a expressão "socar café", o que desde logo assegura a utilização de bateria de pilões. Tais equipamentos, em sua grande maioria, estão associados a estabelecimentos de maior porte, como a fazenda Boa Vista (1882, 282 escravos), que dispunha de uma "casa do Engenho de socar café, com quatro lanços e varanda coberta de telha".

outro equipamento de beneficiamento então em uso na região é o "riba". Trata-se de um engenho constituído de uma calha circular na qual, segundo Taunay, "atritavam por escorregamento lentíssimo regulado pelo passo tardo dos ruminantes [...] duas immensas rodas de cabreúva, pesadíssimas, sobre o café em côco [...] Com o tempo [acrescenta o historiador] o ripes (riba) ou carretão modificou-se [...] e a força propulsora antigamente animada foi substituída pela hidráulica" ${ }^{\prime 3}$. Esses equipamentos eram utilizados por alguns estabelecimentos da região de Bananal, como a fazenda Alambari (1861), que dispunha de "Tres lanços de casas cubertas de telhas com riba". Na fazenda Antinhas (1855), havia "uma caza com Riba", que coexistia com "um engenho de soccar café". Verifica-se, pois, a presença não só desse tipo de equipamento, mas o convívio de mais de um tipo de machina de beneficiamento de café na região.

As tulhas são constantemente mencionadas nos inventários. Sob o aspecto construtivo, é necessário um edifício dotado de condições de conservação e com capacidade de abrigar um determinado volume do produto. Suas descrições aludem, quase invariavelmente, a uma edificação assoalhada sobre porão. Tais requisitos atendem à exigência de propiciar o isolamento dos grãos - da umidade e da ação de insetos e roedores. Para caracterizar a tulha com maior rigor, uma descrição apropriada é aquela relativa à da fazenda da Glória dos Campos. Ali, são mencionados "tres lanços de casas terreas cobertas de telha com duas portas e huma janella na frente do terreiro, e quatro do lado do Rio Bananal, com paredes de adobos, e grande alicerce de pedra, e huma Tulha em cima assualhada, para café". Outro fator de relevância na conservação 
do café é a exigência de dotar o edifício de boa ventilação; nesse caso, atendida pelas aberturas de ambos os lados.

Há, no arrolamento das residências senhoriais ou casas de morada nos inventários, descrições cumulativas de elementos, geralmente correspondentes aos lanços ${ }^{36}$ de que se compõem estas edificações. Quando mais minuciosas, estas descrições se detêm no número de vãos, nas características de fatura ou fazem referência à forma e, muito raramente, mencionam suas divisões internas. Essas últimas podem ser melhor conhecidas por meio da descrição de uma outra categoria de bens, geralmente incluída entre as "madeiras", correspondente ao mobiliário.

Algumas descrições são bastante singelas, como a da fazenda Formoso: "As Casas de morada da Fazenda salinha jardim cusinha e dispensa $[\ldots]^{\prime \prime}$. Outras, como a da fazenda Antinhas, um pouco menos:

Uma morada de casas de vivenda com seis janelas de vidraças e uma porta na frente, com três salas, alcovas, e uma sala de jantar com cantoneira e cozinha imediata, toda coberta de telha [...] e mais [...] uma dita de fronte onde se diz Missa, com onze portas e janelas na frente, com tres cantoneiras e varandas sem grade $[\ldots]^{\prime \prime 37}$.

Esta última descrição corresponde ao conjunto de dependências, típico da casa rural do período do café. Nela comparecem as salas sociais, geralmente situadas na frente, as alcovas no lanço interno, a sala de jantar local de convívio da família - na parte posterior e, finalmente, a cozinha. Não poderia ser mais precisa. A capela, sabidamente um elemento recorrente no programa da fazenda de café, dificilmente aparece nos inventários, a não ser na forma dos oratórios, descritos entre as "madeiras".

Outros arrolamentos de residências importantes repetem o tratamento sumário, salientando apenas algumas de suas peculiaridades: o "mirante" da fazenda Resgate; a "sacada de ferro" da casa de morada da fazenda Bom Retiro; o "sobrado com sótão, gradis de ferro, escadaria do lado" da fazenda Cascata; da "casa de vivenda, assobradada, pintada e impapellada [...] terraço ao lado" da fazenda Independência. Tais ingredientes constituem as variações das monótonas listas dos inventários. Acrescentam alguns dados relativos à forma, dimensão, gosto ou fatura destas residências, sem, no entanto, oferecer avanços à sua interpretação.

$\bigcirc$ que permite ir um pouco além é o exame de alguns arrolamentos em que os bens estão listados em conformidade à sua disposição interna nos cômodos da casa. $\bigcirc$ inventário da fazenda Resgate, de 1878, proporciona um exame meticuloso da sua distribuição interna. Nele são enumerados: "sala de entrada, sala de visitas, $1^{\circ}$ quarto, $2^{\circ}$ quarto e $3^{\circ}$ quarto; escritório, sala de jantar; 1ㅇ quarto na sala de jantar, 2ㅇ quarto na sala de jantar, $3^{\circ}$ quarto, $4^{\circ}$ quarto; sala de costura, $5^{\circ}$ quarto, $6^{\circ}$ quarto e cozinha".

Na sala de visitas é mencionada uma "mobília composta de um sofá, quatro cadeiras de braços e dezoito ditas simples, uma mesa e dois consolos", além de outra "mobília de charão", isto é, de laca, "constando de um sofá, duas cadeiras de braços, seis cadeiras simples, uma mesa de centro e dous consolos
36. A expressão LANÇO foi usada aqui com certa liberdade, porém sem fugir ao sentido que lhe é próprio. Assim, no caso das residências senhoriais, admitimos que, no meio rural, os lanços não eram necessariamente contados perpendicularmente às fachadas, mas paralelos à cumeeira, conforme sugere Carlos Lemos. Quanto às demais instalações, que em geral se resumem a um correr de casas, contamos os lanços como seqüência de cômodos enfileirados.

37. Inventário da fazenda Antinhas compilado por Carlos Eugênio Marcondes de Moura, arquivo do Condephaat. 
com tampos de mármore". Nela sobressai a presença do piano, justificando o grande número de "cadeiras simples", que certamente serviam para acomodar a platéia reunida nos dias de sarau. A sala de visitas é precedida da "sala de entrada" que, com a formalidade típica, é composta de "um sofá, quatro cadeiras de braços, doze cadeiras ditas simples". Considerada a quantidade desse mobiliário, é de se acreditar que este ambiente não era apenas um espaço de distribuição.

A sala de jantar apresenta "uma mesa de jantar e dezoito cadeiras", além do "consolo de marmore". A listagem do mobiliário é concluída com os equipamentos da cozinha, que completam o conjunto de instalações característico da distribuição interna dessas edificações.

Contrasta com as residências senhoriais o outro tipo de habitação característico destes estabelecimentos: a senzala. Destinada a abrigar vastos contingentes de escravos, os testemunhos dessas edificações raramente chegaram até nós. Há, por certo, várias razões. Dentre elas, as características de sua fatura constituem uma das causas que explicam a sua pouca durabilidade. Limitadas ao mínimo necessário à sobrevivência e reprodução da força de trabalho, resultam em instalações precárias, que dificilmente teriam condições de resistir ao tempo.

Embora os inventários constituam fontes de grande importância para a sua compreensão, dificilmente acrescentam algo mais que expressões genéricas sobre sua configuração. A forma mais simples é a seqüência de lanços dispostos em uma só linha, que aparece não apenas nos estabelecimentos mais modestos, "sete lanços de Senzallas cobertas de telhas" (fazenda Cachoeirinha de Baixo, 1836, 26 escravos), mas também nos grandes estabelecimentos, como na fazenda Catadupa, "sinco lanços de casas com varanda que servem de senzallas [...]" e mais "desesseis lanços de Senzallas cubertas de telhas [...]".

Se a disposição linear é a regra geral, há, também, várias descrições de arranjos em "quadra". É o que se pode verificar, entre outras, nas fazendas Antinhas e Boa Vista, que apresentam, respectivamente, "um quadro de senzalas com trinta lanços, e dous portões" (1855, 137 escravos) e "quarenta e cinco lanços de cenzá-las no feicho de dentro, tudo coberto de telhas" (1 882, 287 escravos).

Há, portanto, pelo menos duas formas sistemáticas de organização dessas edificações: as senzalas dispostas em linha e as senzalas dispostas em quadra. Estas últimas parecem corresponder a estabelecimentos de maior porte, com grande número de escravos. Nesse caso, é possível supor que tal disposição seria decorrência da necessidade de abrigar de forma concentrada grandes contingentes de força de trabalho. A concentração em áreas relativamente pequenas devia contribuir, ademais, para atender à necessidade de vigilância e controle dos escravos.

Além da moradia do escravo propriamente dita, há outras dependências a ela associadas, de grande significado para a compreensão da vida nestes estabelecimentos. Trata-se do problema da subsistência e conservação da força de trabalho, que não pode ser entendido em sua inteireza se não se 
considerarem outros dois edifícios associados às senzalas: a cozinha e a enfermaria.

Atendendo à necessidade de alimentar vastos contingentes de trabalhadores, a cozinha pressupõe a existência de um ou mais edifícios especializados. As tarefas ligadas à alimentação nas fazendas constituíam atividades bastante onerosas, seja pela quantidade de bocas a alimentar, seja pelo processo de preparação, que envolvia desde o beneficiamento de gêneros, passando pelas formas de conservação de produtos perecíveis, até, finalmente, o preparo das refeições, por meios não menos complicados que rústicos. De acordo com Stanley Stein, para o preparo das refeições, "[...] havia um fogo aberto sobre o qual penduravam os caldeirões. Ao lado havia mesas de trabalho de madeira, e os grandes pilões [...] peneiras de taquara serviam para separar a casca do arroz ou do milho pilados no pilão; para lavar os alimentos havia grandes e pequenas cuias. Cabaças e pedaços de taquaruçu eram usados para armazenar alimentos, sobretudo gordura"38.

As descrições dos inventários, contudo, não se detêm no interior desses edifícios. São arrolados meramente o número de lanços e, eventualmente, aspectos construtivos. Assim, temos "quatro ditos [lanços] que servem de cuzinha e casas cuberta de telhas [...]" (fazenda Alambari, 1861).

Pouquíssimos exemplos apresentam especificações mais detalhadas, como a fazenda da Divisa (1886, Bananal): "um lanço de casas que serve de cozinha; um lanço de ditas anexo, que serve de dispensa; um lanço de dita onde se faz farinha, contendo prensa e forno de assados", descrição que insinua uma certa especialização de cada uma dessas "casas" para o armazenamento, beneficiamento e preparo. Manifestação mais significativa de especialização é aquela da fazenda Boa Vista, que conta com uma "cozinha de Capados".

Problemas sanitários e de saúde dos trabalhadores faziam parte do cotidiano das fazendas de café. Tais condições estão presentes nos inventários, os quais, ao relacionar individualmente as "peças" da escravaria, não deixavam de mencionar o seu estado. Os percentuais relativos ao contingente de escravos inválidos, mencionados por Stein, oscilam em torno de $20 \%$ da força de trabalho. Bem ou mal, era necessário dotar o estabelecimento de um edifício, ainda que precário, capaz de propiciar o isolamento e as condições de assistência aos enfermos. Em grande parte dos inventários, aparece a enfermaria e, entre as mais opulentas, como a fazenda Boa Vista, há referência - além dos "cinco lanços que servem de enfermaria" - a uma "Botica com varanda".

Tratadas as duas habitações principais, não é possível esquecer que, do programa dos estabelecimentos de café, fazem parte outros tipos de moradias e acomodações, permanentes ou temporárias. Além das casas de eventuais agregados, seja no "quadro" da fazenda, seja no "campo" ou nas localidades indicadas pelos topônimos peculiares, há aquelas que constituem parte indissociável destes estabelecimentos e neles aparecem destacadas: a casa do feitor e a casa do administrador.

Dessas edificações temos referências sumárias nos inventários, tais como: "dois lanços de ditas para administrador [...]" (fazenda Paineiras, 1888); 
"uma dita para o feitor e empregados [...]" (fazenda São Joaquim do Barreiro de Baixo, 1883); "a casa do feitor, coberta de telhas" (fazenda Carrapato, 1883); "dois lanços de Casas para o administrador" (fazenda Catadupa, 1866); "uma casa para feitor, com um quarto para tenda e um puchado para estrebaria" (fazenda Boa Vista, 1875). Não há muito mais que isso. Como se verifica nas descrições, os arrolamentos apenas mencionam a existência de tais casas, sem enumerar detalhes ou características.

Mencionados em vários inventários, há, por fim, os ranchos. A descrição mais expressiva é daquele da Boa Vista:

[...] nove lanços de Casas a beira da Estrada geral, cobertos de telha, que servem de Rancho de passageiros, com dous lanços feixados que servem de Casa de Negócio, tendo em cada hum destes, hum Balcão e parteleiras e hum dos ditos sendo assoalhado: todos os dois com nove portas, e quatro janellas incluzive hum pequeno puxado que serve de cozinha (fazenda Boa Vista, 1875).

A bela descrição destas habitações temporárias completa o repertório desses edifícios. Resta agora examinar sua arquitetura.

A arquitetura das fazendas de café

conjunto formado pelos vários edifícios que constituem a sede de uma fazenda de café organiza-se, quase invariavelmente, em quadra. Podem variar os esquemas de organização ou pode o conjunto ser constituído de mais de um quadro; enfim, o que define a forma característica de sua organização é a possibilidade de resumir as instalações a essa figura recorrente. À forma inicial podem agregar-se apêndices; novos terreiros podem surgir fora do perímetro original e, em torno deles, novas edificações virem a se acomodar. De um modo ou de outro, tudo se organiza em torno da quadra ou dos quadros. Pode mesmo ocorrer que os quadros não sejam inteiramente fechados ou tenham, como muitas vezes acontece, um dos lados completados por um muro ou ainda pelo jardim. que importa é que a forma final resultante é o quadro.

E é lógico que assim fosse. Tais arranjos são feitos, em geral, à volta do terreiro. Porém esse não é o único fator condicionante. A topografia do sítio, aliada à indispensável oferta de água para movimentar as máquinas, é o outro. Nessas circunstâncias, resta às edificações ocupar o perímetro lindeiro das plataformas de secagem. Há, além disso, componentes subsidiários que contribuem, também eles, para a agregação de quadros ao conjunto principal, tais como o pátio das tropas, o pomar, o jardim ou mesmo as áreas reservadas à criação, quase sempre cercados por muros, a reproduzir a forma inicial.

Por maior que seja o número de variações, há dois tipos fundamentais de arranjos do conjunto das instalações. $\bigcirc$ primeiro deles adota um esquema muito regular, constituído de um quadro bem alinhado, em que a distribuição das partes é perfeitamente ordenada. A residência senhorial está localizada em 
posição de destaque, no centro de uma composição cujas massas se distribuem de maneira rigorosamente simétrica. No segundo, como resultado de terrenos mais difíceis, a residência principal comparece deslocada em relação ao eixo principal da composição. Assimetria, aqui, não significa de modo nenhum desequilíbrio do conjunto, cuja harmonia é resolvida pelo jogo alternado entre as massas.

exemplo paradigmático do primeiro tipo é, sem dúvida, a fazenda Boa Vista. Além do que os restos existentes permitem inferir, a iconografia demonstra-o plenamente. A fazenda Rialto também se alinha neste grupo (Figura 3). São expressões nas quais o conjunto está submetido a um rígido controle, subordinado a uma ordem abstrata em que todos os elementos estão organizados segundo uma hierarquia bem definida. $\bigcirc$ sentido de forma fechada, característico deste esquema, é acentuado pela disposição da maioria das aberturas, orientadas para o interior do quadro.

Sempre em torno dos pátios e das plataformas de secagem, porém em situações de topografia acidentada - exigindo a construção de enormes muros de contenção -, encontram-se os exemplares que fogem ao padrão anterior. Valendo-se muitas vezes de uma sucessão de planos, que vão se acomodando ao terreno, estes conjuntos oferecem um jogo de massas muito rico e variado. O exemplar mais conhecido é o da fazenda Pau d'Alho, em São José do Barreiro. Implantada à meia-encosta, suas edificações estão distribuídas em sucessivos patamares. Ao fundo, em cota superior, situa-se o pomar; em seguida, o platô

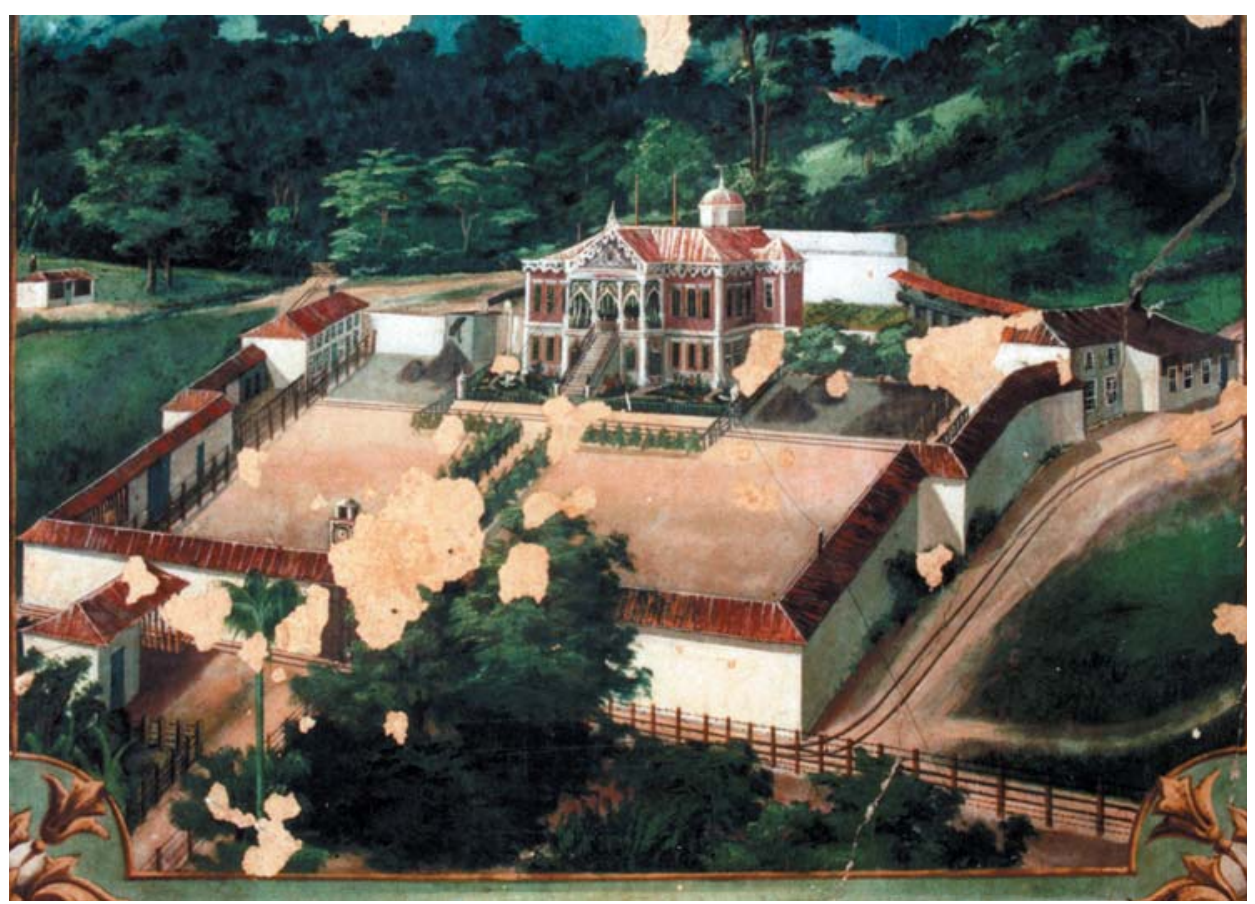

Figura 3 - José Maria Vilaronga [atribuição], Fazenda Rialto, Bananal, SP, pintura mural. Fotografia de Marcos José Carrilho. 
das senzalas e depois o do terreiro. Confina com este último, numa de suas bordas, a casa de morada, que tem dois pequenos pátios lindeiros, além de um outro destinado às tropas. A composição é dominada pelos muros que recortam a paisagem com longas linhas contínuas, proporcionando grande unidade ao conjunto (Figura 4).

A fazenda Catadupa é outro exemplo que reproduz, à semelhança da Pau d'Alho, um agenciamento assimétrico. O sítio é até mais adverso, a julgar pela posição de suas máquinas, encostadas nas corredeiras do ribeirão Formoso.

Tais esquemas são tributários da oferta de água para movimentar as máquinas. Sua organização depende da presença do canal d'água que percorre uma das faces do quadro e que, ao longo deste alinhamento, serve o lavador de café, o poço de maceração, o engenho ou a casa de máquinas, os moinhos; e que, em alguns casos, distribui água para aproveitamento doméstico.

Os canais e regos d'água da fazenda Pau d'Alho ilustram bem tal afirmação. Depois de bordejar a encosta por longo percurso, ao se aproximar das instalações, o rego muda de direção e, adotando o alinhamento das edificações, alcança a roda d'água. Na seqüência, após ter recebido as águas servidas e já em cota inferior, alimenta a turbina do primeiro moinho e, mais abaixo, movimenta o segundo. O suceder de quedas e as mudanças de nível determinam a posição e a cota dos edifícios de beneficiamento e vinculam a sua disposição.

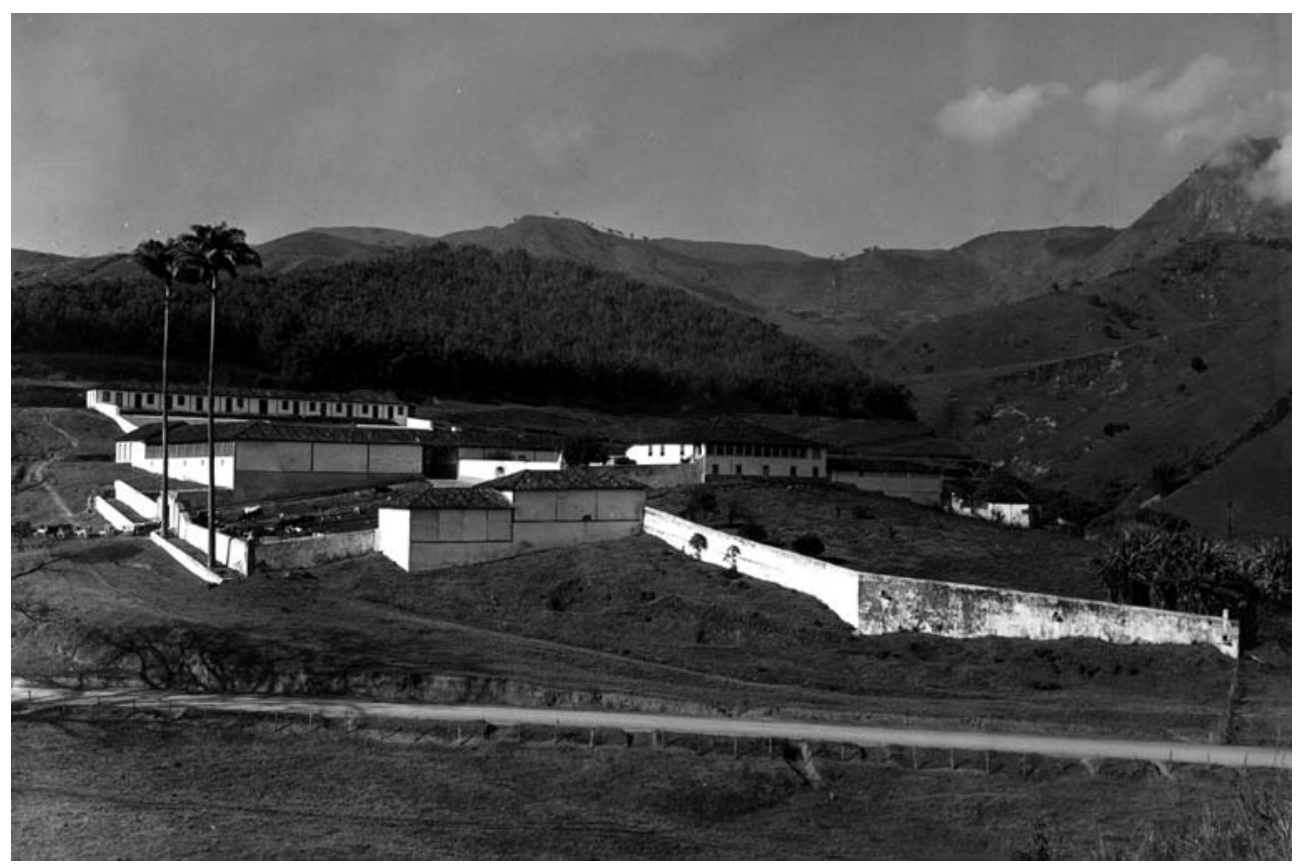

Figura 4 - Fazenda Pau d'Alho, São José do Barreiro, SP. Fotografia de Germano Graeser. Acervo do Instituto do Patrimônio Histórico e Artístico Nacional (IPHAN), 9a. SR, São Paulo. 
Dispositivo bastante requintado é aquele existente na fazenda Coqueiros, em Bananal. Trata-se de um extenso canal subterrâneo, que corre paralelo à estrada ao longo de uma das faces das instalações. A água, obtida por meio de pequeno represamento na embocadura do canal, é distribuída em três pontos para as diferentes finalidades, a saber: a primeira derivação dirigese ao engenho junto à casa de morada; a segunda alimenta o lavador de café; e, finalmente, o canal desemboca na direção de outro engenho, do qual restam apenas ruínas. $\bigcirc$ primeiro desses regos servia ainda para movimentar um moinho, depois de ter recolhido as águas servidas da residência. $\bigcirc$ segundo canal, após ter atendido o lavador, prossegue por debaixo dos terreiros pavimentados. Ao longo de seu percurso há duas aberturas, provavelmente para recolher as águas desses terraplenos. Eis a demonstração do grau de sofisticação atingido por esse sistema; e da importância da água, seja como força motriz, seja como recurso auxiliar no beneficiamento do café. Assim, a posição da fonte hídrica organiza a distribuição das instalações e determina suas cotas e níveis. Quando necessário, alguns artifícios proporcionam uma relativa autonomia em relação ao alinhamento do rego, permitindo potencializar o seu aproveitamento.

$\bigcirc$ terreiro ocupa, em geral, a área privilegiada do sítio onde se implanta a sede da fazenda. $\bigcirc$ vazio central formado por esta enorme superfície plana, cujo revestimento absorve e concentra o calor do sol, era o espaço para onde se voltavam as edificações. Foi talvez a visão deste espaço inóspito, desprovido de qualquer fator de amenização, onde transcorria a faina quase solitária dos negros a revolver o café, que levou Agassiz a comentar: "Os grãos se estendem sobre um cimento de brancura ofuscante cuja claridade, sob este céu escaldante, é insuportável e obriga logo a gente a descansar a vista em algum trato de verdura" ${ }^{\prime \prime}$.

Eis por que alguns dos agenciamentos mais habilidosos afastam ligeiramente do terreiro, por meio de um pequeno jardim, a residência senhorial, como o demonstram os exemplos das fazendas Resgate, Boa Vista, Rialto e Pau d'Alho.

A casa de máquinas é, com certeza, uma das edificações mais importantes de um estabelecimento de café, pois dela depende a eficiência do beneficiamento da produção. São poucos os exemplares remanescentes. $\bigcirc$ traço comum dessas edificações é a construção em sobrado. Corrobora essa proposição o relato da visita a uma fazenda do Vale do Paraíba fluminense feita por Herbert Smith, por volta de 1880. Na ocasião, o cientista norte-americano anotou minuciosamente as operações de beneficiamento, que utilizam ventiladores, despolpadores e separadores. Essas operações pressupõem manobras de elevação do produto, que exigem um pé-direito alto e, conseqüentemente, construção em sobrado ${ }^{40}$.

Esta descrição é ilustrada de forma precisa pelos levantamentos do engenho da fazenda Santana, em Areias. $\bigcirc$ referido engenho dispunha de uma variedade de equipamentos de beneficiamento e, no caso do café, era dotado de uma máquina Lidgerwood, composta de despolpador, abanador e classificador, além de elevador de grãos. Constituído de quatro corpos - que
39. AGASSIZ, Luiz;AGASSIZ, Elizabeth C. Viagem ao Brasil. São Paulo: Nacional, 1938, p. 154.

40. SMITH, Herbert $\mathrm{H}$. Uma fazenda de café no tempo do Império. Rio de Janeiro: Departamento Nacional do Café, 1941, p. 22 
41. SAINT-HILAIRE, Augusto. Viagem pelas Províncias do Rio de Janei ro a Minas Gerais. São Paulo: Comissão do IV Centenário da Cidade de São Paulo; Martins,p. 189

42. Em Lemos (1999), o capítulo "A casa do início da era cafeeira, no Vale do Paraíba: programas desse tempo" é muito esclarecedor a respeito das ati vidades no interior da casa senhorial (LEMOS, 1999, p. 133-204) abrigavam a roda d'água, as máquinas e uma peque, na tulha -, o edifício era organizado em vários níveis, com o corpo principal em três pisos. A captação de água era feita na encosta adjacente e conduzida em nível ligeiramente mais alto que a roda d'água, contando esta com um complexo sistema de transmissão de energia.

Embora voltados para a produção e concebidos, portanto, dentro de estritas exigências funcionais, esses edifícios não eram desprovidos de atenção formal. Os refinados trabalhos de cantaria nas ruínas da casa de máquinas da fazenda da Barra não deixam de revelar a intenção de dotar também estes edifícios de atributos artísticos.

As residências senhoriais apresentam-se segundo três tipos básicos: sobrados, casas térreas, ou aquelas que conjugam simultaneamente a condição de edificação assobradada de um lado e térrea de outro. Apesar dessas variações, os exemplares observados guardam uma semelhança desconcertante, pois tendem a reproduzir quase invariavelmente a mesma organização interna. "Dar a conhecer a fazenda do Itajurú" - afirmou Saint-Hilaire - "é fornecer uma idéia geral de grande número de habitações." ${ }^{\text {Al }}$

A disposição com salas na frontaria, alcovas e quartos no lanço intermediário, sala de jantar ou varanda na banda posterior e, finalmente, cozinha e dependências de serviços no puxado é o esquema de organização que se generaliza. Assobradada ou não, esta forma recorrente é conseqüência do fato de a residência propriamente dita realizar-se em um único piso.

Tal arranjo sistemático é, sem dúvida, decorrente de formas de comportamento social consolidadas, cuja expressão característica se resume no estabelecimento de dois setores fortemente diferenciados, em que os limites eram determinados pela nítida separação entre o universo da vida social e o da vida privada.

Esta rígida organização espacial, porém, não permaneceu totalmente fechada. A vida social, apesar de conservar hábitos e preconceitos arcaicos, evoluiu. Embora ainda persistisse a segregação da vida familiar, desenvolveramse novas formas de sociabilidade, como claramente demonstra o mobiliário que habitava tais edificações. As salas são, agora, locais de grande atividade social, que adquiriu certo refinamento e ilustração, e em cujos saraus a música e a poesia são presenças obrigatórias ${ }^{42}$.

Neste ambiente, não há mais lugar para o alpendre característico da arquitetura que conhecemos no século anterior. Os acessos às residências, quando feitos por meio de escadas, terminam num patamar alargado, um pouco mais generoso, destinado, mais do que à permanência, às formalidades de bem receber. A própria sala de entrada, espaço especializado de distribuição, já denota a ausência do alpendre. Eventuais exemplares em que este elemento está presente revelaram, logo ao primeiro exame, tratar-se de alteração posterior. Se não há alpendre, nestes edifícios comparecem partes de grande importância arquitetônica: a escada e o patamar de acesso. Compostas muitas vezes de 
volumes destacados dos edifícios, estes corpos vigorosos de alvenaria de pedra, quase sempre no centro da composição, são produto de elaboração bastante refinada. A sua presença confirma que, embora assobradada, a residência situase, mesmo, no pavimento superior.

Os interiores contrastam com as feições austeras do volume externo. São profusamente decorados. Com freqüência, os forros apresentam painéis trabalhados entre molduras e cordões, arrematados por cornijas com desenho de gosto neoclássico. $\bigcirc$ mesmo tratamento se repete nos caixilhos e bandeiras, cujas divisões resultam em rendilhados caprichosos, emoldurados por guarnições arrematadas por algum relevo em leque. Na segunda metade do século XIX, barramentos de escaiola, frisos de douração e papel de parede importado não eram raros nesses ambientes.

$\bigcirc$ volume arquitetônico das casas senhoriais reproduz quase sempre a mesma forma, composta de um prisma retangular com telhado em pavilhão (em quatro águas), e com o ritmo invariável dos vãos, vez por outra animados por uma cercadura mais rebuscada ou pelo destaque atribuído ao acesso principal. Tais prismas são, quando muito, marcados nos cunhais por pilastras, algumas delas ostentando capitéis e fustes trabalhados.

A decoração externa destes edifícios limita-se à utilização dessa escassa ornamentação com motivos clássicos, confinada às vergas ou bandeiras dos vãos, aos cunhais e à porta principal. Não comparecem aí platibandas, frontões, corpos salientes ou divisões tripartidas das fachadas, então em voga nos ambientes mais cosmopolitas, especialmente nas residências urbanas do Rio de Janeiro.

Porém, se os ares ilustrados da corte não foram fortes o suficiente para alcançar plenamente esta região, isso não significa que não houvesse realizações arquitetônicas dignas de destaque. Entre as residências senhoriais, a fazenda Resgate é, certamente, uma das mais importantes. $\bigcirc$ que a singulariza é o agenciamento de sua capela. Embora a residência mantenha a organização usual, composta dos três lanços característicos distribuídos no nível superior, a capela ocupa dois pavimentos, tendo a nave pé-direito duplo ${ }^{43}$. Tal particularidade estabelece uma escala inusitada, permitindo o desenvolvimento do altar em altura. Parcialmente sobreposta à nave, a sala de visitas se abre para a capela, à feição de coro e tribunas, arrematadas pelo arco-cruzeiro (Figura 5). Se, de um lado, esse engenhoso expediente atende aos imperativos de segregação social, confere, de outro, um sentido verdadeiramente monumental à capela. A residência apresenta, ainda, rico tratamento decorativo em seu interior, graças à pintura mural de Vilaronga, cujos efeitos de trompe l'oeil dividem as atenções com temas alegóricos e motivos nativos de fauna e flora.

Assim, se, como resultado dos imperativos da produção de café em face das condições específicas do meio, esta região pioneira alcançou uma síntese particular na organização geral destes estabelecimentos - expressa por uma tipologia arquitetônica particular, que abrange desde a organização dos 


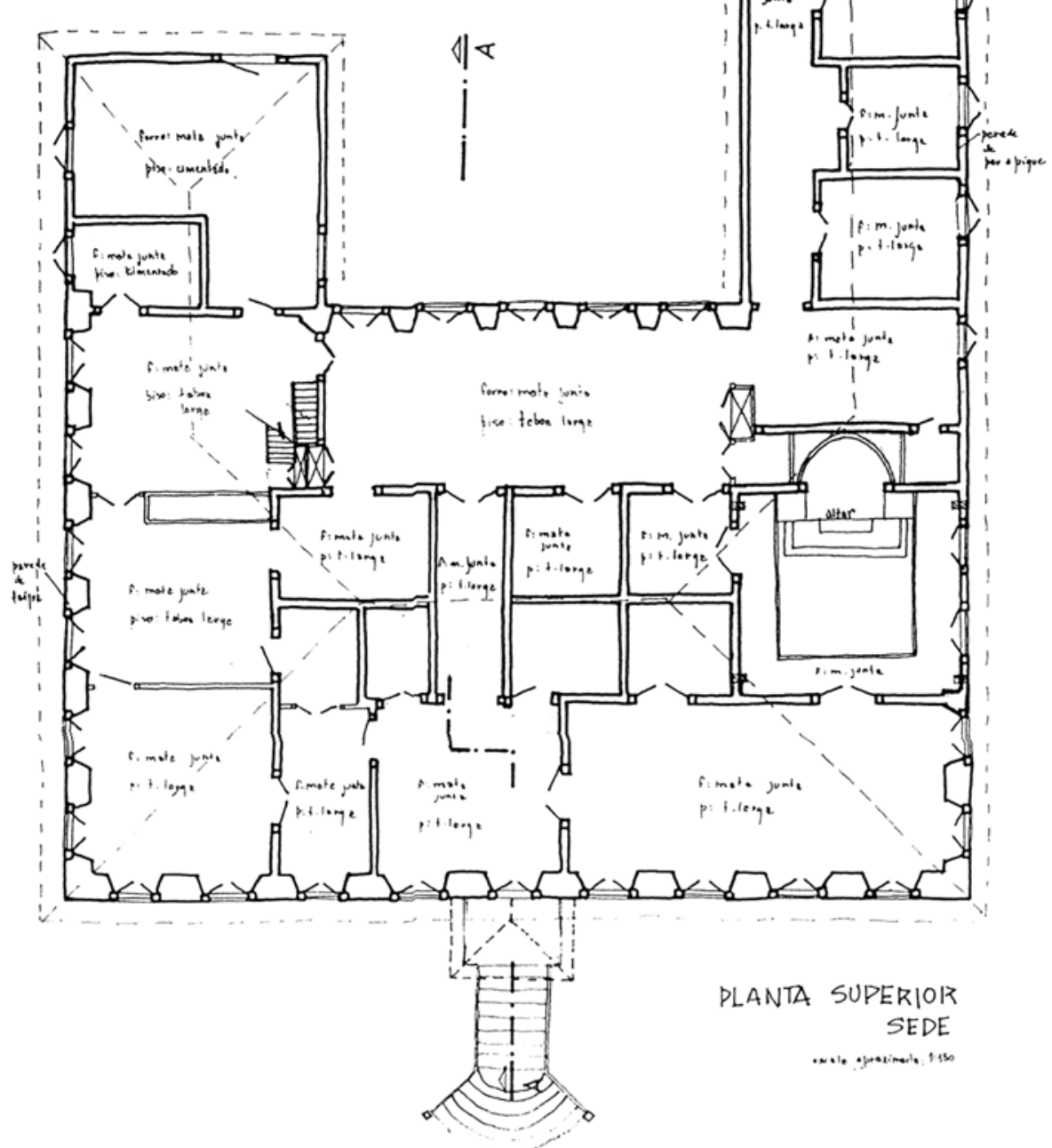

Figura 5 - Planta da residência da Fazenda Resgate, Bananal, SP (Série "Levantamento preliminar de fazendas do Vale do Paraíba"). Acervo do Conselho de Defesa do Patrimônio Histórico, Artístico, Arqueológico e Turístico do Estado de São Paulo, Condephaat, São Paulo. 
edifícios até o arranjo do conjunto -, atingiu também um alto grau de realização arquitetônica. É o que se pode ainda perceber a partir do arranjo das instalações e das notáveis obras de cantaria de pedra. Tal configuração é tão forte que, embora muitas das edificações não tenham subsistido, persiste a ampla superfície dos terreiros, com seus patamares e muros como a marca mais evidente da passagem da cultura do café. Em seus restos ainda é possível verificar a presença do domínio técnico então alcançado, demonstração da habilidade e refinamento atingidos.

Mas a presença desses vestígios assinala, também, a existência de outro componente singular: a paisagem do café. Esta paisagem, manifestada principalmente na transformação radical do ambiente, com a expansão do cultivo do café em substituição às florestas, também está presente em uma outra escala, na sede do estabelecimento agrícola. Comparece na abertura dos caminhos, na implantação dos edifícios, na repartição das áreas destinadas ao cultivo de subsistência, ao pasto, à horta, ao pomar e, finalmente, ao jardim. Este último teria aparecido talvez pela primeira vez de forma sistemática no meio rural.

Se a paisagem original dos mares de morros foi brutalmente alterada com a eliminação do vasto manto de mata atlântica, reduzida a escassos nichos quase inatingíveis, parecem ter sido plantadas - paradoxalmente - as primeiras manifestações de construção de um universo paisagístico próprio e marcadamente brasileiro. Nova paisagem, intimamente associada à arquitetura, sendo uma a referência da outra: a presença da sede da fazenda, que o renque de palmeiras imperiais, à distância, anuncia.

\section{REFERÊNCIAS}

AGASSIZ, L.; AGASSIZ, E. C. Viagem ao Brasil. São Paulo: Nacional, 1938.

LABORIE, P. J. O fazendeiro de café na ilha de São Domingos. In: O fazendeiro do Brazil. Rio de Janeiro: Officinas de S.T. Ferreira, 1799.

LEMOS, C.A. C. Casa Paulista: história das moradias anteriores ao ecletismo trazido pelo café. São Paulo: Edusp, 1999.

MOURA, C. E. M. Inventários de proprietários de fazendas de café do Vale do Paraíba.Arquivos do Conselho de Defesa do Patrimônio Histórico,Arqueológico,Artístico e Turístico do Estado de São Paulo - Condephaat, São Paulo.

REBELLO, J. S. Memória sobre a cultura do cafeeiro. O Auxiliador da Indústria Nacional, Rio de Janeiro, n. 5, 1833.

SAIA, L. Notas preliminares sobre a fazenda Pau d'Alho. Separata de: Revista de História, São Paulo, n. 102, 1975. 
SMITH, H. H. Uma fazenda de café no tempo do Império. Rio de Janeiro: Departamento Nacional do Café, 1941.

STEIN, S. Grandeza e decadência do café. São Paulo: Brasiliense, 1961.

TAUNAY, A. d'E. História do café. Rio de Janeiro: Departamento Nacional do Café, 1939.

WERNECK, F. P. L. (Barão de Paty do Alferes). Memória sobre a fundação de uma fazenda na Provícia do Rio de Janeiro. Rio de Janeiro, Fundação Casa de Rui Barbosa, 1985.

Artigo apresentado em 06/2005. Aprovado em 03/2006. 